\title{
Factors Associated with Delayed Paracentesis in Patients with Spontaneous Bacterial Peritonitis
}

\author{
Backer Abdu $^{1}$ [ $\cdot$ Shalaka Akolkar ${ }^{1} \cdot$ Christopher Picking ${ }^{1} \cdot$ Judith Boura ${ }^{1} \cdot$ Marc Piper $^{1}$
}

Received: 30 May 2020 / Accepted: 25 November 2020 / Published online: 3 December 2020

(c) The Author(s) 2020

\begin{abstract}
Background and Aim In patients with spontaneous bacterial peritonitis (SBP), studies show that delayed paracentesis (DP) is associated with worse outcomes and mortality. We aimed to assess the rate of DP in the community setting and associated factors with early versus delayed paracentesis.

Methods Patients hospitalized with SBP were retrospectively studied between 12/2013 and 12/2018. DP was defined as paracentesis performed $>12 \mathrm{~h}$ from initial encounter. Data collected included: patient factors (i.e., age, race, symptoms, history of SBP, MELD) and physician factors (i.e., admission service, shift times, providers ordering and performing paracentesis). Logistic regression analysis was performed to assess for factors associated with DP.

Results DP occurred $82 \%$ of the time $(n=97)$. The most significant factors in predicting timing of paracentesis were ordering physician [emergency department (ED) physician was associated with early paracentesis $(57 \%$ vs $8 \%, p<0.001)$ and specialty of physician performing paracentesis (interventional radiology was associated with DP ( $88 \%$ vs $48 \%, p<0.001)$ ]. Younger patients were more likely to receive early paracentesis. In regression analysis, the factor most associated with early paracentesis was when the order was made by the ED provider (OR 0.07, 95\% CI 0.02-0.22). No differences were observed in patients with prior history of SBP, abdominal pain, encephalopathy, or creatinine level.

Conclusions Studies have suggested that DP is associated with increased mortality in patients with SBP. Despite this, DP is common in the community setting and is influenced by ordering physician and specialty of physician performing paracentesis. Future efforts should assess interventions to improve this important quality indicator.
\end{abstract}

Keywords Delayed paracentesis $\cdot$ Spontaneous bacterial peritonitis $\cdot$ Ascites

\section{Introduction}

Spontaneous bacterial peritonitis (SBP) is the most frequent infectious complication in hospitalized patients with cirrhosis [1]. Mortality rates have been observed up to $46 \%$ inhospital and $66 \%$ at 12 months in patients with SBP [2-4].

The presentation of SBP is often atypical, with too few symptoms or with signs and symptoms common to other conditions making clinical identification a challenge. Yet the prevalence is significantly high in hospitalized patients with cirrhosis and ascites even when clinical suspicion is

Backer Abdu

Backer2238@gmail.com

1 Department of Gastroenterology and Internal Medicine, Providence-Providence Park Hospital, Michigan State University College of Human Medicine, 16001 W Nine Mile Rd, Southfield, MI 48075, USA low [5], necessitating a diagnostic paracentesis for correct identification.

Given the high mortality and frequency of SBP in hospitalized cirrhotic patients with ascites, society guidelines have recommended paracentesis performed in any patient with cirrhosis and ascites admitted to the hospital $[6,7]$. However, despite these practice guideline recommendations, diagnostic paracentesis is done in only $61 \%$ of indicated patients within the USA [8]. Accordingly, a set of quality indicators were developed by an expert panel for the care of patients with cirrhosis, in which a diagnostic paracentesis in patients admitted to the hospital was identified as one of the most important explicit indicators of quality [9].

Previous studies have observed increased in- and out-ofhospital mortality following delays in the performance of paracentesis. In a multicenter study comparing early paracentesis (EP) vs delayed paracentesis (DP), there was a 2.7-fold increased risk of mortality in hospitalized patients 
with SBP receiving DP [10]. As shown by the Cooperative Antimicrobial Therapy of Septic Shock (CATSS) Database Research Group, the timely diagnosis of SBP is crucial as each hour in delay is associated with a twofold increase in in-hospital mortality [11]. In a study analyzing veteran inpatients with cirrhotic ascites, early paracentesis was as important as MELD in predicting intermediate term survival following SBP [12]. Although a clear benefit is observed, firm conclusions to reasons for underutilization of EP is lacking.

The aim of this study is to evaluate the rate of DP in cirrhotic patients with SBP admitted to the community hospital setting along with barriers associated with early vs delayed performance of paracentesis.

\section{Methods}

\section{Study Overview}

In this retrospective cohort study, we analyzed data on patients with a diagnosis of SBP who were hospitalized in 1 of 4 community hospitals from December 2013 to December 2018. Trained abstractors collected patient data from electronic medical records (EMR) using a standard protocol and data collection template. The patient cohort was obtained from different hospitals that share the same inpatient database and EMR. These four hospitals were selected for their diverse populations and represent different areas of Michigan.

This study was approved by the institutional review board overseeing research performed at these hospitals.

\section{Patients}

Adult patients aged 18 years or over with a discharge diagnosis of SBP who underwent paracentesis during their inpatient stay were included in the study. Patients with a history of cirrhosis and ascites on admission were eligible for inclusion. Abstractors identified cirrhotic patients by medical history and clinical findings consistent with cirrhosis. We excluded those who were found to have other potential contributing causes of peritonitis (including peritoneal dialysis patients, active intra-abdominal malignancies, or previous history of intra-abdominal organ transplantation).

SBP was defined using International Classification of Diseases, 9th Revision-Clinical Modification (ICD-9) and 10th Revision-Clinical Modification (ICD-10) codes 567.23 and K65.2, respectively. Paracentesis was identified by Current Procedural Terminology codes 49082 and 49083. Patients were considered to have EP if it was performed within $12 \mathrm{~h}$ from the moment of initial encounter with a medical provider. The time of initial encounter was defined by the date and time of evaluation provided in the clinical documents or the first order placed by a medical provider in the EMR (whichever came first). The date and time of paracentesis performed was defined by information obtained in the procedure note or the time in which the ascitic fluid analysis order was changed from "ordered" status to "inprocess" status (whichever came first).

\section{Covariates}

Data for all patients with a diagnosis of SBP were abstracted directly from the EMR and included demographic characteristics, clinical history, characteristics of clinical presentation, and laboratory values. Severity of hepatic dysfunction was calculated using the Model for End-Stage Liver Disease (MELD) score using the initial laboratory values on admission. Provider characteristics, including hospital location, admission service, specialty of provider ordering and performing paracentesis, and shift times of initial encounter were also collected from the EMR.

The etiology of cirrhosis was obtained from the initial providers' documentations. If the etiology was not clearly noted, it was obtained from the medical problem list or other providers' documentation notes. History of SBP, past medical history, and active malignancy were defined by identifying the presence of documentation acknowledging such history in the initial provider notes. The clinical symptoms, physical examination findings, and home medications were also obtained by the initial providers' documentation. The first recorded vital signs and laboratory values from the EMR were used. If more than one ascitic fluid analysis was performed during an admission, only the initial analysis was used.

\section{Outcomes}

The primary outcome of interest was performance of DP ( $>12 \mathrm{~h}$ of initial encounter by medical provider) among all patients diagnosed with SBP. Secondary outcomes included factors associated with timing of paracentesis performed, length of stay, and all-cause inpatient mortality.

\section{Statistical Analysis}

All data were analyzed using SAS for Windows ${ }^{\circledR}$, version 9.4 (SAS Institute, Cary, NC). Categorical variables were provided as counts or percent frequencies and were examined with Chi-square tests where appropriate (expected frequency $>5$ in $80 \%$ of cells); otherwise, Fisher's Exact tests were used. All continuous variables were provided as either means ( \pm the standard deviation or median and 25th and 75 th percentiles), followed by the minimum to maximum dependent on the normality of the data. Continuous data were examined with Wilcoxon rank sum tests. Multivariable 
logistic regression analysis for the primary outcome and for inpatient mortality were performed using all covariates analyzed with a univariate $p$ value $<0.10$ or those known to specifically impact outcomes. WALD odds ratios were used to assess significance with $95 \%$ confidence intervals. All analysis used a 2-tailed alpha level of 0.05 .

\section{Results}

\section{Overall Characteristics of Study Cohort}

During the study period, 216 patients were identified as having a diagnosis of SBP with a paracentesis procedure performed. These patients were analyzed for documentation confirming a history of cirrhosis and ascites along with an identifiable etiology.

Of the total patients identified, patients who did not have cirrhosis after analyzing their charts were excluded (34 patients). Patients who had other competing causes of peritonitis such as secondary bacterial peritonitis, pancreatitis, or infectious colitis (39 patients) and patients with ascitic PMH counts $<250$ (16 patients) were excluded. Nine patients had multiple admissions in which only the first available visit was kept, rendering a total of 118 patients in our final analysis. See Fig. 1 for more details.

The median age of patients was 62 years, $56.8 \%$ were male, $59.7 \%$ were Caucasian, $50.4 \%$ of patients had Medicare/Medicaid insurance, and $41.2 \%$ had cirrhosis attributed to alcohol abuse. $18.5 \%$ of patients had a documented history of previous SBP, and the median MELD score was 22.0 [interquartile range (IQR) 14.0-28.3]. Along with SBP, patients identified with initial concomitant GI bleed, encephalopathy, and elevated creatinine level were $15.1 \%$, $38.7 \%$, and $23.5 \%$, respectively. Patient demographic characteristics are listed in Table 1. Of the total number of patients with SBP, $71.4 \%$ were admitted to a private (nonacademic) service, $65.6 \%$ initially presented during a day shift (6 a.m. -6 p.m.), $80.7 \%$ received antibiotics prior to paracentesis, and $80.7 \%$ had paracentesis performed by interventional radiology (IR) service. The median time to paracentesis in those who received EP was $3.5 \mathrm{~h}$ (IQR 2.4-8.9) compared to those who received DP which was $39.7 \mathrm{~h}$ (IQR 31.3-81.5) $(p<0.001)$.

\section{Primary Outcome: Rate of Delayed Paracentesis}

DP occurred in $82 \%$ of patients $(n=97)$. No differences were observed between all four hospital locations. The median time to paracentesis from initial encounter with a medical provider for all patients with SBP was $27.6 \mathrm{~h}$ (IQR 17.8-56.9). Of the patients who received DP, there were no statistically significant differences in patient gender, race, or service admitted to. The median length of stay (LOS) for these patients was 7.7 days (IQR 4.0-11.9).

Patients who were most likely to have undergone DP were those in which paracentesis was performed by IR service (87.6\% vs. $47.6 \%, p=0.0002)$. In comparison, EP was most often performed when the order for paracentesis was made by the emergency department (ED) provider (57.1\% vs. $8.3 \%, p<0.0001)$, regardless of who performed the paracentesis procedure (Fig. 2).

\section{Secondary Outcomes: Factors Associated with Early Versus Late Paracentesis}

There was no statistically significant difference between EP and DP in patients presenting with a prior history of SBP $(p=0.22)$, abdominal pain $(p=0.10)$, encephalopathy $(p=0.06)$, or creatinine level $(p=0.32)$. Variables associated with early versus delayed paracentesis are listed in Table 2.

A multivariable logistic regression analysis adjusting for age, sex, MELD score, shift time of paracentesis, provider ordering paracentesis, the presence of encephalopathy, and tachycardia was performed to identify independent factors associated with EP vs DP during hospitalization. Paracentesis ordered by the ED physician was associated with decreased odds of receiving a DP [odds ratio (OR) 0.07 ; $95 \%$ confidence interval (CI) $0.02-0.22, p<0.05]$, regardless of which provider performed the procedure. The odds of receiving DP was greater with younger age (per every 10-year interval) (OR 1.85; 95\% CI 1.08-3.16, $p<0.05$ ) and with increasing maximum heart rate (per every $10 \mathrm{bpm}$ ) on initial presentation (OR 1.40; 95\% CI 1.03-1.89, $p<0.05$ ) (Table 3).

\section{Length of Stay}

Although unable to reach statistical significance, there was a clinical trend toward longer median LOS in patients who received a DP [7.7 days, (IQR 4.0, 11.9) compared to patients with EP (5.9 days, (IQR 2.7, 8.5) $(p=0.07)]$

\section{Inpatient Mortality}

Patients were also assessed for inpatient mortality in which $40 \%(n=48)$ of all patients with SBP died during hospitalization. Of those who suffered inpatient mortality, $64.6 \%$ $(n=31)$ were Caucasian, $77.1 \%(n=37)$ were admitted to a nonacademic service, $83.3 \%(n=40)$ received DP, and $12.5 \%(n=6)$ had the paracentesis ordered by an ED provider. The patients that died during hospitalization were statistically more likely to have higher INR, MELD score, creatinine, total bilirubin, and lactic acid levels, with lower albumin levels compared to those who survived at discharge. 


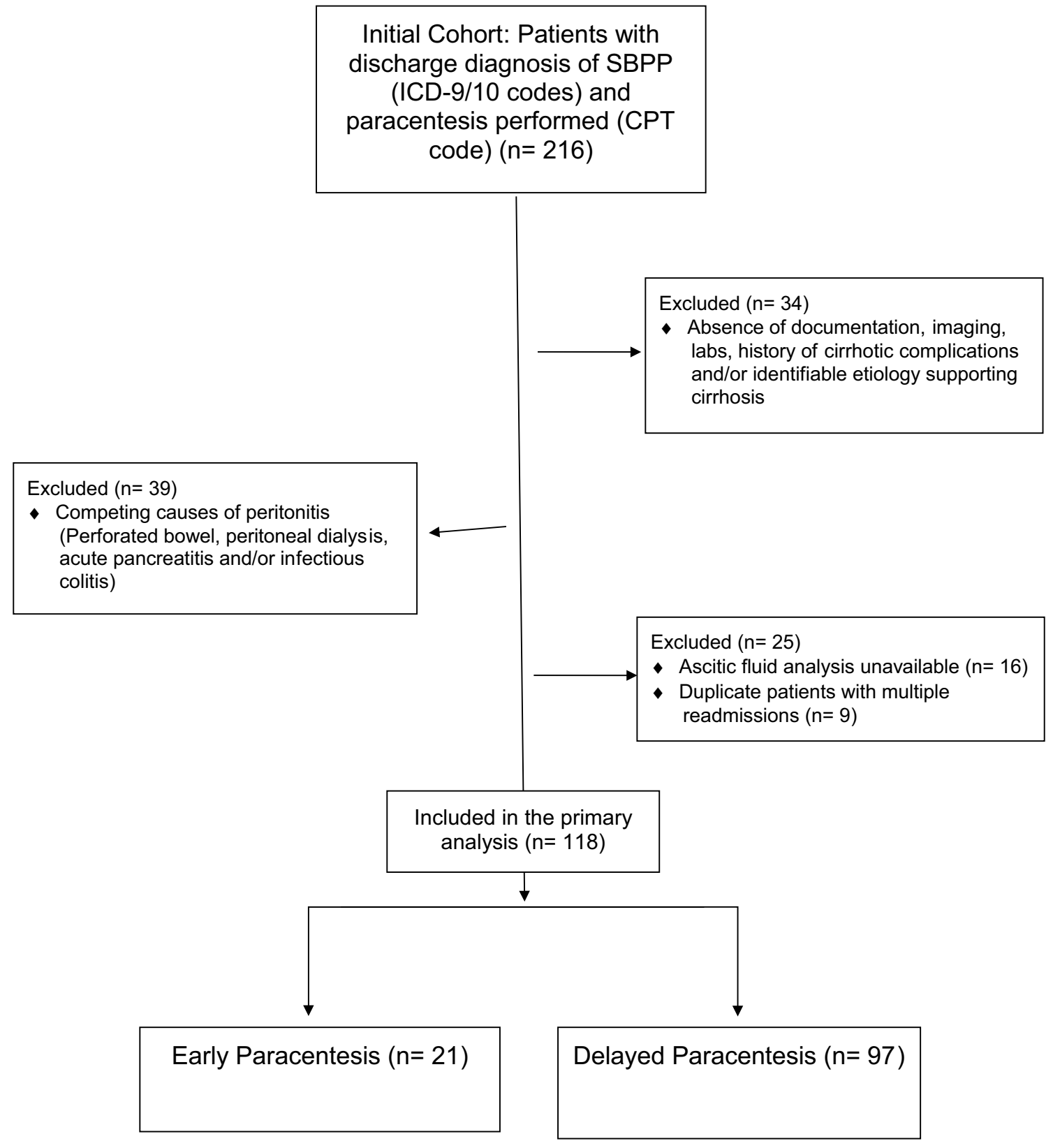

Fig. 1 Flow diagram for cohort selection

Furthermore, patients with inpatient mortality were also more likely to have hepatic encephalopathy $(50 \%)$ than those who were discharged alive (31\%) (OR 2.23; 95\% CI 1.04-4.75, $p=0.037$ ) (Table 4).

DP was found to be non-statistically associated with inpatient mortality (OR 1.14; 95\% CI 0.43-3.01, $p=0.79$ ). On multivariable step-down logistic regression analysis adjusting for age, sex, presence of encephalopathy, INR, MELD score, creatinine, total bilirubin, and albumin levels, only low albumin levels and higher MELD scores were significant predictors of inpatient mortality (OR 2.44; 95\% CI $1.25-4.76$ ) and (OR 1.05; 95\% CI 1.003-1.09).

\section{Discussion}

Using data from four hospitals in which patients were diagnosed with SBP, we found that approximately $80 \%$ of patients underwent DP. In addition, the odds of receiving DP was significantly less when the decision to pursue a paracentesis was made by the ED provider. Of note, most patients who received a DP were those in which the procedure was performed by IR service. Furthermore, patients who were younger and presented with a higher maximum heart rate were also more likely to undergo DP. 
Table 1 Overall baseline description of patients and variables collected for analysis

Overall descriptive data of cohort

\begin{tabular}{|c|c|c|}
\hline & Frequency $(n)$ & Percent \\
\hline \multicolumn{3}{|l|}{ Sex } \\
\hline Male & 67 & 57 \\
\hline Female & 51 & 43 \\
\hline \multicolumn{3}{|l|}{ Race } \\
\hline Caucasian & 71 & 60 \\
\hline African American & 44 & 37 \\
\hline Hispanic/Native American & 1 & 1 \\
\hline Other & 2 & 2 \\
\hline \multicolumn{3}{|l|}{ Insurance } \\
\hline Medicare & 50 & 42 \\
\hline Medicaid & 10 & 8 \\
\hline BlueCross & 21 & 18 \\
\hline Molina & 8 & 7 \\
\hline Humana & 3 & 3 \\
\hline Private/other & 26 & 23 \\
\hline \multicolumn{3}{|l|}{ Hospital location } \\
\hline Hospital 1 & 32 & 27 \\
\hline Hospital 2 & 19 & 16 \\
\hline Hospital 3 & 15 & 13 \\
\hline Hospital 4 & 52 & 44 \\
\hline \multicolumn{3}{|l|}{ Admission service } \\
\hline Academic & 30 & 26 \\
\hline Private & 85 & 71 \\
\hline Other & 3 & 3 \\
\hline \multicolumn{3}{|l|}{ Provider ordering paracentesis } \\
\hline ED & 20 & 17 \\
\hline Primary service & 55 & 46 \\
\hline Gastroenterology service & 19 & 16 \\
\hline Infectious disease service & 3 & 3 \\
\hline ICU & 15 & 13 \\
\hline Other & 6 & 5 \\
\hline \multicolumn{3}{|c|}{ Provider performing paracentesis } \\
\hline ED & 7 & 6 \\
\hline Primary service & 6 & 5 \\
\hline Interventional radiology & 96 & 81 \\
\hline ICU & 8 & 7 \\
\hline Other & 1 & 1 \\
\hline \multicolumn{3}{|l|}{ Shift time of initial encounter } \\
\hline 6:00-18:00 & 78 & 66 \\
\hline 18:01-5:59 & 40 & 34 \\
\hline \multicolumn{3}{|l|}{ Shift time of paracentesis order } \\
\hline 6:00-18:00 & 97 & 82 \\
\hline $18: 01-5: 59$ & 21 & 18 \\
\hline \multicolumn{3}{|l|}{ Etiology of liver disease } \\
\hline Alcohol & 49 & 41 \\
\hline Hepatitis B/C & 22 & 19 \\
\hline NAFLD & 38 & 32 \\
\hline Autoimmune & 2 & 2 \\
\hline
\end{tabular}


Table 1 (continued)

Overall descriptive data of cohort

\begin{tabular}{|c|c|c|}
\hline & Frequency $(n)$ & Percent \\
\hline History of SBP & 22 & 18 \\
\hline On SBP prophylaxis & 18 & 15 \\
\hline On antiplatelet and/or anticoagulation & 22 & 18 \\
\hline History of renal disease & 28 & 24 \\
\hline Active malignancy & 28 & 24 \\
\hline \multicolumn{3}{|l|}{ Clinical history on initial presentation } \\
\hline Abdominal pain & 85 & 71 \\
\hline Abdominal distention & 104 & 87 \\
\hline Encephalopathy & 46 & 39 \\
\hline GI bleed & 18 & 15 \\
\hline Antibiotics administered prior to paracentesis & 96 & 80.7 \\
\hline \multirow[t]{2}{*}{ Inpatient mortality } & 48 & 40 \\
\hline & Median & IQR range \\
\hline Age & 62 & $56-69$ \\
\hline Maximum temperature $\left({ }^{\circ} \mathrm{C}\right)$ & 36.8 & $36-37.4$ \\
\hline Maximum heart rate (beats per minute) & 104 & $92-120$ \\
\hline Platelet count $\times 1000(\mathrm{~K} / \mathrm{mcL})$ & 189 & $120-175$ \\
\hline INR & 1.51 & $1.28-1.8$ \\
\hline Creatinine level (mmol/dL) & 1.25 & $0.90-2.70$ \\
\hline Sodium level (mmol/L) & 134 & $130-137$ \\
\hline Total bilirubin level $(\mathrm{mmol} / \mathrm{L})$ & 1.70 & $0.80-4.30$ \\
\hline Albumin level (g/dL) & 2.5 & $2.1-3.0$ \\
\hline Lactic acid level (mmol/L) & 2.5 & $1.5-4.9$ \\
\hline MELD-Na score & 22 & $14.0-28.3$ \\
\hline Time to paracentesis (h) & 27.6 & $17.8-56.9$ \\
\hline Length of stay (days) & 7.0 & $3.8-11.2$ \\
\hline
\end{tabular}

\section{Variables Significantly Associated with Delayed Paracentesis}

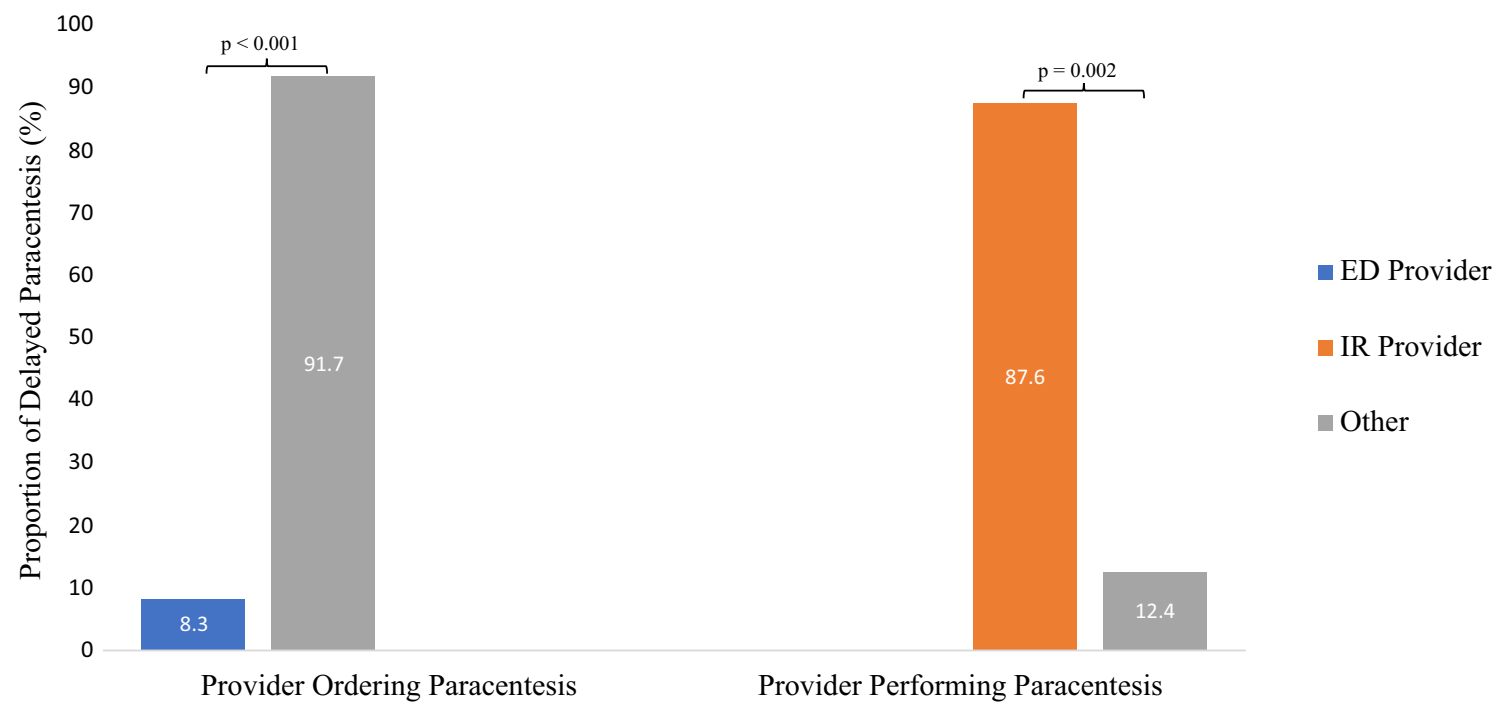

Fig. 2 Percentage of patients who received a delayed paracentesis based on ordering provider and provider performing paracentesis 
Table 2 Patient demographics and provider characteristics associated with early vs delayed paracentesis

\begin{tabular}{|c|c|c|c|}
\hline & $\begin{array}{l}\text { Early paracentesis } \\
N=21\end{array}$ & $\begin{array}{l}\text { Delayed paracentesis } \\
N=97\end{array}$ & $P$ value \\
\hline \multicolumn{4}{|l|}{ Patient demographics } \\
\hline Female & $9(42.9 \%)$ & $42(43.8 \%)$ & 0.94 \\
\hline Median age, years (min-max) & $60(34-76)$ & $63(30-89)$ & 0.14 \\
\hline Caucasian race & $13(61.9 \%)$ & $58(59.8 \%)$ & 0.86 \\
\hline \multicolumn{4}{|l|}{ Insurance } \\
\hline Medicare/Medicaid & $11(52.4 \%)$ & $48(49.5 \%)$ & 0.61 \\
\hline BC/BS, Molina, Humana & $4(19.1 \%)$ & $28(28.9 \%)$ & \\
\hline Private/other & $6(28.6 \%)$ & $21(21.7 \%)$ & \\
\hline \multicolumn{4}{|l|}{ Hospital location } \\
\hline Hospital 1 & $8(38.1 \%)$ & $44(45.4 \%)$ & Ref \\
\hline Hospital 2 & $7(33.3 \%)$ & $25(25.8 \%)$ & 0.65 \\
\hline Hospital $3 \& 4$ & $6(28.6 \%)$ & $28(28.9 \%)$ & 0.85 \\
\hline \multicolumn{4}{|l|}{ Etiology of liver disease } \\
\hline Alcohol & $8(61.5 \%)$ & $40(52.0 \%)$ & 0.90 \\
\hline Hepatitis B/C & $2(15.4 \%)$ & $21(27.3 \%)$ & \\
\hline Alcohol/Hep B/C & $2(15.4 \%)$ & $10(13.0 \%)$ & \\
\hline NAFLD & $1(7.7 \%)$ & $6(7.8 \%)$ & \\
\hline Autoimmune & 0 & $2(2.5 \%)$ & \\
\hline Prior history of SBP & $6(28.6 \%)$ & $16(16.5 \%)$ & 0.22 \\
\hline On prophylactic treatment & $4(19.1 \%)$ & $14(14.4 \%)$ & 0.74 \\
\hline On antiplatelet/anticoagulant & $5(23.8 \%)$ & $17 / 96(17.7 \%)$ & 0.54 \\
\hline Active malignancy & $4(19.1 \%)$ & $24(24.7 \%)$ & 0.78 \\
\hline History of DM & $5(23.8 \%)$ & $29(29.9 \%)$ & 0.58 \\
\hline History of renal disease & $5(23.8 \%)$ & $22(22.7 \%)$ & 1.00 \\
\hline Abdominal pain & $18(85.7 \%)$ & $66(68.0 \%)$ & 0.10 \\
\hline Abdominal distention & $19(90.5 \%)$ & $84(86.6 \%)$ & 1.00 \\
\hline GI Bleed & $3(14.3 \%)$ & $15(15.5 \%)$ & 1.00 \\
\hline Encephalopathy & $12(57.1 \%)$ & $34(35.1 \%)$ & 0.06 \\
\hline MELD score (median, IQR) & $23.2(15.4,28.3)$ & $21.7(13.8,28.2)$ & 0.38 \\
\hline Max temperature ${ }^{\circ} \mathrm{C}$ (median, IQR) & $36.7(36.4,37.1)$ & $36.9(36.6,37.4)$ & 0.26 \\
\hline Max heart rate, beats per minute (median, IQR) & $92(80,118)$ & $105(97,120)$ & 0.07 \\
\hline White blood cell count, $\mathrm{K} / \mu \mathrm{L}$ (median, IQR) & $9.5(7.9,14.0)$ & $11.8(7.6,18.1)$ & 0.15 \\
\hline Platelet count, $\mathrm{K} / \mu \mathrm{L}$ (median, IQR) & $179(124,266)$ & $167(96,236)$ & 0.51 \\
\hline INR level (median, IQR) & $1.50(1.24,1.68)$ & $1.54(1.30,1.80)$ & 0.38 \\
\hline Creatinine level, mmol/L (median, IQR) & $1.42(1.07,2.40)$ & $1.20(0.90,2.68)$ & 0.32 \\
\hline Sodium level, mmol/L (median, IQR) & $135(128,138)$ & $134(130,137)$ & 0.78 \\
\hline Total bilirubin level, $\mu \mathrm{mol} / \mathrm{L}$ (median, IQR) & $32(14,91)$ & $27(15,70)$ & 0.97 \\
\hline Albumin level g/L (median, IQR) & $2.7(2.2,3.0)$ & $2.4(2.1,3.0)$ & 0.81 \\
\hline Lactic acid level, mmol/L (median, IQR) & $2.90(1.5,6.7)$ & $2.30(1.4,4.6)$ & 0.47 \\
\hline \multicolumn{4}{|l|}{ Provider characteristics } \\
\hline \multicolumn{4}{|l|}{ Admission service } \\
\hline Private hospitalist service versus academic service & $18(85.7 \%)$ & $66(68.0 \%)$ & 0.10 \\
\hline \multicolumn{4}{|l|}{ Provider ordering paracentesis } \\
\hline ED provider versus all others & $12(57.1 \%)$ & $8(8.3 \%)$ & $<0.0001$ \\
\hline \multicolumn{4}{|l|}{ Provider performing paracentesis } \\
\hline IR provider versus all others & $10(47.6 \%)$ & $85(87.6 \%)$ & 0.0002 \\
\hline \multicolumn{4}{|l|}{ Shift of initial encounter } \\
\hline Day (06:01-18:00) & $12(57.1 \%)$ & $65(67.0 \%)$ & 0.39 \\
\hline Night (18:01-06:00) & $9(42.9 \%)$ & $32(33.0 \%)$ & \\
\hline Shift of paracentesis ordered & & & \\
\hline
\end{tabular}


Table 2 (continued)

\begin{tabular}{lccc}
\hline & $\begin{array}{l}\text { Early paracentesis } \\
N=21\end{array}$ & $\begin{array}{l}\text { Delayed paracentesis } \\
N=97\end{array}$ & $P$ value \\
\hline Day (06:01-18:00) & $14(66.7 \%)$ & $82(84.5 \%)$ & 0.069 \\
Night (18:01-06:00) & $7(33.3 \%)$ & $15(15.5 \%)$ & \\
Length of stay, days (median, IQR) & $5.9(2.7,8.5)$ & $7.7(4.0,11.9)$ & 0.07 \\
Inpatient mortality & $8(38.1 \%)$ & $40(41.2 \%)$ & 0.79 \\
\hline
\end{tabular}

Table 3 Factors associated with delayed paracentesis

\begin{tabular}{llc}
\hline Factor & Multivariable OR $(95 \%$ CI $)$ & $P$ value \\
\hline Age (per every 10-year decrease interval) & $1.85(1.08-3.16)$ & 0.03 \\
Female & $0.83(0.39-1.75)$ & 0.88 \\
ED provider ordering paracentesis & $0.07(0.02-0.22)$ & $<0.0001$ \\
Heart rate (per every 10-bpm increase interval) & $1.40(1.03-1.89)$ & 0.03 \\
Encephalopathy & $2.23(1.04-4.75)$ & 0.11 \\
\hline
\end{tabular}

This data confirms that DP is common in patients with SBP and discordant with current guidelines and recommendations. Our findings are consistent with other studies in which less than $60 \%$ of admissions met quality care criteria $[9,13,14]$. Although this study was not designed to answer a direct causal relationship, it was able to identify a strong association between ED physicians' orders and time to performance of paracentesis. Correspondingly, in a study assessing cirrhosis-associated ED visits, all complications of cirrhosis had decreased over time except for SBP, which continued to escalate [15]. A few explanations to these findings seem plausible. First, the ED location may influence utilization of quality care by facilitating interventions more promptly. When the order for paracentesis is made by the ED provider, it is done by the ED provider at bedside or the need of such procedure is communicated and responded to in a more urgent fashion. This is supported by the many studies and guidelines published to increase ED consultation efficiency [16]. However, in a national US survey, over $90 \%$ of large hospitals report EDs operating at or over capacity [17]. As such, extensive efforts have been targeted to reduce overcrowding and improve patient flow by decreasing total ED LOS [18]. Although no studies were found that assess procedures times related to ED LOS, a $964 \%$ increase in paracentesis procedures performed by IR is thought to arise secondary to time constraints and reimbursements [19]. Such outcomes may significantly reduce early bedside paracentesis performed by ED physicians. This is further supported by a recent quality improvement project where a gap analysis performed to identify barriers to paracentesis reported that time and personnel required in the ED were the most common reasons cited [20].

Second, as the signs and symptoms of SBP are often atypical and non-specific, a low index of suspicion for SBP may prolong time to paracentesis. This may explain the findings of those with higher heart rates being associated with DP. However, in a study assessing 144 patients undergoing paracentesis in the ED, physicians performed poorly at predicting SBP using clinical characteristics and physician assessment [5]. Nonetheless, this should not preclude nor delay paracentesis in such patients. Another potential reason is inadequate training in performing paracentesis procedures. In a study assessing procedure rates performed by ED residents in a large emergency medicine program in the USA, the average number of paracentesis performed was only 0.39 per year [21]. Such low rates are likely inadequate to be fully comfortable with performing bedside paracentesis ultimately leading to IR consultations and delayed paracentesis.

Interestingly, even a prior history of SBP did not affect the rates of EP vs DP. Multiple studies have shown the recurrence rate of SBP in patients with previous episodes is $>40 \%$ $[22,23]$. Given that a prior documented history did not affect the timing of paracentesis is another troublesome finding as recurrence of SBP is known to be associated with higher mortality [24].

Although DP did not definitively influenced mortality rates or LOS, a clinically significant increase in LOS trended toward DP procedures, consistent with other studies [11-13, 28]. We also found $80.7 \%$ of patients received antibiotics prior to paracentesis. Hence the timing of antibiotics may have influenced the association between DP and mortality. This practice may provoke a false sense of reassurance to providers and obscure the presence of SBP when a DP is performed.

This study, however, has its limitations. Studies with larger populations are necessary to detect further differences with statistical significance. Nonetheless, our population size in a five-year period is comparable with other published literature assessing patients with SBP [10, 11, 24-29]. Karvellas et al. [11] analyzed aspects of antimicrobial therapy to 
Table 4 Patient demographics and provider characteristics associated with inpatient mortality

Alive at discharge $\mathrm{N}=71$

Expired during hospitalization $P$ value $\mathrm{N}=48$

\section{Patient demographics}

\section{Female}

Median age, years (min to max)

Caucasian race

Etiology of liver disease

Alcohol
Hepatitis B/C
Alcohol/Hep B/C
NAFLD
Autoimmune
Active malignancy
History of DM
History of renal disease
GI bleed
Encephalopathy
MELD score (median, IQR)
Max temperature ${ }^{\circ} \mathrm{C}$ (median, IQR)
Max heart rate, beats per minute (median, IQR)
White blood cell count, K/ $\mu \mathrm{L}$ (median, IQR)
Platelet count, K/ $\mu \mathrm{L}$ (median, IQR)
INR level (median, IQR)
Creatinine level, mmol/L (median, IQR)
Total bilirubin level, $\mu$ mol/L (median, IQR)
Albumin level g/L (median, IQR)
Lactic acid level, mmol/L (median, IQR)
Provider characteristics
Admission service
Private hospitalist service versus academic service
Provider ordering paracentesis
ED provider versus all others
Provider performing paracentesis
IR provider versus all others
Delayed paracentesis

$32(45.1 \%)$
$62(30-88)$
$40(56.3 \%)$
$26(51.0 \%)$
$12(23.5)$
$7(13.7 \%)$
$5(9.8 \%)$
$1(2.0 \%)$
$18(25.4 \%)$
$22(31.0 \%)$
$19(26.8 \%)$
$10(14.1 \%)$
$22(31.0 \%)$
$18.9(10.8,26.7)$
37.0
$104(92,119)$
$10.7(7.3,17.9)$
$155(85,228)$
$1.41(1.20,1.70)$
$1.14(0.82,2.40)$
$1.3(0.6,3.2)$
$2.7(1.8,4.0)$
$1.9(1.4,3.3)$

$48(67.6 \%)$

$14(19.7 \%)$

$60(84.5 \%)$

$57(81.4 \%)$

$\begin{array}{ll}19(40.4 \%) & 0.62 \\ 62(39-89) & 0.96 \\ 31(64.6 \%) & 0.37 \\ & \\ 23(54.8 \%) & 0.92 \\ 11(26.2 \%) & \\ 5(11.9 \%) & \\ 2(4.8 \%) & \\ 1(2.4 \%) & \\ 10(20.8 \%) & 0.57 \\ 13(27.1) & 0.65 \\ 9(18.8 \%) & 0.31 \\ 8(16.7 \%) & 0.70 \\ 24(50 \%) & 0.037 \\ 25.3(17.7,30.7) & 0.004 \\ 36.8 & 0.25 \\ 107(91,120) & 0.58 \\ 12.8(8.216 .8) & 0.24 \\ 190(110,251) & 0.20 \\ 1.71(1.42,2.25) & 0.003 \\ 1.65(1.09,2.83) & 0.049 \\ 2.7(1.2,5.2) & 0.004 \\ 2.3(1.4,3.3) & 0.001 \\ 3.6(2.3,5.9) & 0.008 \\ & \\ 37(77.1 \%) & 0.79 \\ 6(12.5 \%) & \\ 36(75 \%) & \\ 40(83.3 \%) & \\ & \\ & \\ & \\ & \\ & \\ & \\ & \end{array}$

mortality in patients with SBP from an international multicenter database over a 15-year time span, yielding a cohort of 126 patients. In three studies assessing factors associated with recurrence of SBP, 139 patients over a 4-year period, 124 patients over a 3-year period, and 111 patients in a 1 -year analysis have contributed to practice changing results [22, 24, 27]. In addition, other studies of patients with SBP have shown in-hospital mortality rates of $37-81 \%$, which encompass similar results to our cohort, allowing generalizability to other populations with SBP [10, 11, 13, 27-29]. However, approximately $40 \%$ of our population had active malignancy, which is considerably higher than other studies that range from 7.2 to $18 \%[10,13,28]$. This proportion may reflect a sicker population; however, even small variations can yield significant changes in the proportion of a small sample size.

Moreover, a large proportion of our initial cohort was excluded due to secondary bacterial peritonitis, which suggests ambiguities and misdiagnosis codes that may hinder correct acquisition of information. Nonetheless, our selection process consisted of a sensitive method of acquiring the initial population followed by a negative selection criteria to ensure a specified cohort. We used ICD-9/10 codes as previous studies showed sufficient sensitivity and specificity in identifying such patients. Kanwal et al. [14] found high accuracy in database-derived definitions of cirrhotic complications when compared with diagnoses derived by structured and detailed review of charts. Specifically, the 
database definition of SBP using $\geq 250$ PMNs in ascitic fluid analysis yielded an $88 \%$ PPV and 95\% NPV in identifying SBP. In an analysis of 2893 subjects, Nehra et al. [30] found that the single ICD-9 code 567.23 for SBP carried a specificity of $98.9 \%$ with a PPV of $84.1 \%$. A recent study evaluating the accuracy of ICD-10 codes for cirrhosis and its complications in a nationwide sample found them to be highly predictive and reliable, similar to validation studies of ICD-9 codes [31].

Another limitation is the exclusion of subsequent admissions for an individual patient. This was done to independently analyze the association of factors to outcomes specified. As we defined history of SBP by the documentation acknowledging such history, the exclusion of subsequent admissions may have consequently weakened this approach. We also did not differentiate between anticoagulation and antiplatelet use as, per AASLD guidelines, coagulopathy should only preclude paracentesis when there is clinically evident fibrinolysis or DIC [32]. Furthermore, the 2019 society of Interventional Radiology suggests not withholding anticoagulation or antiplatelets for low-risk procedures, including paracentesis [33]. However, these guidelines may not be well known to non-GI and non-IR physicians.

Of note, the median time to paracentesis was $27.6 \mathrm{~h}$ (IQR 17.8-56.9), signifying that most cases were within the time definition of community-acquired SBP. There were 20 cases, however, where the diagnosis of SBP was made after $72 \mathrm{~h}$, of these $40 \%(n=8)$ were diagnosed within 5 days and $70 \%$ $(n=14)$ diagnosed within 7 days, rendering the time-sensitive diagnostic criteria of nosocomial SBP to be uncertain. Marginal cases have the potential of being misclassified and managed differently due to delays in diagnosis.

Despite clear evidence showing the importance of performing EP in patients admitted with cirrhosis and ascites, too few are done within a recommended timeframe. Given the high risk of adverse outcomes in patients with SBP, along with the inability to detect SBP using signs and symptoms with adequate sensitivity, strategies are needed to improve the implementation of EP. While DP is common, this study has provided a clearer causal pathway, analyzing multiple aspects of patient care, as to why this occurs. Ultimately, the initial provider present during patient presentation is crucial for directing management. Strategies aimed at barriers to performing EP should be directed toward encouraging paracentesis performance in the ED, regardless of physician specialty. Many EDs have optimized their ability to deliver quality care for critical conditions such as trauma, acute coronary syndromes, and strokes by implementing guidelines for time-sensitive management resulting in life-saving consequences. A similar approach should be given toward patients with cirrhosis. In addition, assessment of competency in performing bedside paracentesis may also be needed to increase performance by non-IR providers.
Increasing the awareness of recommendations and benefits of performing EP in hospitalized patient with cirrhosis and ascites may also improve adherence to this quality indicator.

In conclusion, despite previous evidence suggesting increased mortality with delayed paracentesis leading to recommendations for the performance of early paracentesis, we found that delayed paracentesis is common in the community setting. Creating interventions to improve early paracentesis in patients with SBP is of primary concern. Future large qualitative and quantitative studies are needed to assess physician and systemic barriers in providing this quality indicator.

\section{Compliance with Ethical Standards}

Conflict of interest No conflicts of interest exist for all authors.

Open Access This article is licensed under a Creative Commons Attribution-NonCommercial 4.0 International License, which permits any non-commercial use, sharing, adaptation, distribution and reproduction in any medium or format, as long as you give appropriate credit to the original author(s) and the source, provide a link to the Creative Commons licence, and indicate if changes were made. The images or other third party material in this article are included in the article's Creative Commons licence, unless indicated otherwise in a credit line to the material. If material is not included in the article's Creative Commons licence and your intended use is not permitted by statutory regulation or exceeds the permitted use, you will need to obtain permission directly from the copyright holder. To view a copy of this licence, visit http://creativecommons.org/licenses/by-nc/4.0/.

\section{References}

1. Caly WR, Strauss E. A prospective study of bacterial infections in patients with cirrhosis. J Hepatol. 1993;18:353-358. https://doi. org/10.1016/S0168-8278(05)80280-6.

2. Nobre SR, Cabral JEP, Gomes JJF, Leitão MC. In-hospital mortality in spontaneous bacterial peritonitis: a new predictive model. Eur J Gastroenterol Hepatol. 2008;20:1176-1181. https://doi. org/10.1097/MEG.0b013e32830607a2.

3. Rockey DC. Infection-related mortality in patients with cirrhosis. Am J Med Sci. 2018;355:102-103. https://doi.org/10.1016/j. amjms.2017.12.020.

4. Arvaniti V, D'Amico G, Fede G, et al. Infections in patients with cirrhosis increase mortality four-fold and should be used in determining prognosis. Gastroenterology. 2010;139:1246-1256.e5. https://doi.org/10.1053/j.gastro.2010.06.019.

5. Chinnock B, Afarian H, Minnigan H, Butler J, Hendey GW. Physician clinical impression does not rule out spontaneous bacterial peritonitis in patients undergoing emergency department paracentesis. Ann Emerg Med. 2008;52:268-273. https://doi. org/10.1016/j.annemergmed.2008.02.016.

6. Garcia-Tsao G, Lim J. Management and treatment of patients with cirrhosis and portal hypertension: recommendations from the Department of Veterans Affairs Hepatitis C Resource Center Program and the National Hepatitis C Program. Am J Gastroenterol. 2009;104:1802-1829. https://doi.org/10.1038/ajg.2009.191. 
7. Ginès $P$, Angeli $P$, Lenz K, et al. EASL clinical practice guidelines on the management of ascites, spontaneous bacterial peritonitis, and hepatorenal syndrome in cirrhosis. J Hepatol. 2010;53:397417. https://doi.org/10.1016/j.jhep.2010.05.004.

8. Orman ES, Hayashi PH, Bataller R, Barritt AS. Paracentesis is associated with reduced mortality in patients hospitalized with cirrhosis and ascites. Clin Gastroenterol Hepatol. 2014;12:496503.e1. https://doi.org/10.1016/j.cgh.2013.08.025.

9. Kanwal F, Kramer J, Asch SM, et al. An explicit quality indicator set for measurement of quality of care in patients with cirrhosis. Clin Gastroenterol Hepatol. 2010;8:709-717. https://doi. org/10.1016/j.cgh.2010.03.028.

10. Kim JJ, Tsukamoto MM, Mathur AK, et al. Delayed paracentesis is associated with increased in-hospital mortality in patients with spontaneous bacterial peritonitis. Am J Gastroenterol. 2014;109:1436-1442. https://doi.org/10.1038/ajg.2014.212.

11. Karvellas CJ, Abraldes JG, Arabi YM, Kumar A. Appropriate and timely antimicrobial therapy in cirrhotic patients with spontaneous bacterial peritonitis-associated septic shock: a retrospective cohort study. Aliment Pharmacol Ther. 2015;41:747-757. https ://doi.org/10.1111/apt.13135.

12. Blais P, Huh A, Nayak L, Elwing JE, Sayuk GS. 704-Survival benefit associated with early detection of spontaneous bacterial peritonitis (SBP) in veteran inpatients with cirrhotic ascites. Gastroenterology. 2018;154:S-144. https://doi.org/10.1016/s0016 $-5085(18) 30900-4$.

13. Rosenblatt R, Tafesh Z, Shen N, et al. Early paracentesis in highrisk hospitalized patients: time for a new quality indicator. $\mathrm{Am}$ J Gastroenterol. 2019;114:1863-1869. https://doi.org/10.14309 /ajg.0000000000000443.

14. Kanwal F, Kramer JR, Buchanan P, et al. The quality of care provided to patients with cirrhosis and ascites in the Department of Veterans Affairs. Gastroenterology. 2012;143:70-77. https://doi. org/10.1053/j.gastro.2012.03.038.

15. Pant C, Olyaee M, Gilroy R, et al. Emergency department visits related to cirrhosis. Medicine (Baltimore). 2015;94:e308. https:// doi.org/10.1097/MD.0000000000000308.

16. Guertler AT, Cortazzo JM, Rice MM. Referral and consultation in emergency medicine practice. Acad Emerg Med. 2008;1:565-571. https://doi.org/10.1111/j.1553-2712.1994.tb02557.x.

17. Trzeciak S, Rivers EP. Emergency department overcrowding in the United States. Emerg Med J. 2003;20:402-405. https://doi. org/10.1136/emj.20.5.402.

18. Elder E, Johnston ANB, Crilly J. Review article: systematic review of three key strategies designed to improve patient flow through the emergency department. Emerg Med Australas. 2015;27:394-404. https://doi.org/10.1111/1742-6723.12446.

19. Duszak R, Chatterjee AR, Schneider DA. National fluid shifts: fifteen-year trends in paracentesis and thoracentesis procedures. J Am Coll Radiol. 2010;7:859-864. https://doi.org/10.1016/j. jacr.2010.04.013.

20. Jesudian A, Barraza L, Steel P, et al. Quality improvement initiative increases total paracentesis and early paracentesis rates in hospitalised cirrhotics with ascites. Frontline Gastroenterol. 2020;11:22-27. https://doi.org/10.1136/flgastro-2019-101199.

21. Bucher JT, Bryczkowski C, Wei G, et al. Procedure rates performed by emergency medicine residents: a retrospective review. Int J Emerg Med. 2018;11:7. https://doi.org/10.1186/s1224 5-018-0167-x.
22. Abdel-Razik A, Abdelsalam M, Gad DF, et al. Recurrence of spontaneous bacterial peritonitis in cirrhosis. Eur J Gastroenterol Hepatol. 2020;32:718-726. https://doi.org/10.1097/MEG.00000 00000001578.

23. Huang CH, Lin CY, Sheen IS, et al. Recurrence of spontaneous bacterial peritonitis in cirrhotic patients non-prophylactically treated with norfloxacin: serum albumin as an easy but reliable predictive factor. Liver Int. 2011;31:184-191. https://doi.org/10. 1111/j.1478-3231.2010.02377.x.

24. Nair SV. Predictors of recurrent spontaneous bacterial peritonitis in patients with cirrhosis of liver. J Clin Exp Hepatol. 2018;8:S58. https://doi.org/10.1016/j.jceh.2018.06.376.

25. Brooling J, Ghaoui R, Lindenauer PK, Friderici J, Lagu T. Use of paracentesis in hospitalized patients with decompensated cirrhosis and ascites: opportunities for quality improvement. J Hosp Med. 2014;9:797-799. https://doi.org/10.1002/jhm.2275.

26. Le S, Spelman T, Chong CP, et al. Could adherence to quality of care indicators for hospitalized patients with cirrhosisrelated ascites improve clinical outcomes? Am J Gastroenterol. 2016;111:87-92. https://doi.org/10.1038/ajg.2015.402.

27. Musskopf MI, Fonseca FP, Gass J, de Mattos AZ, John JA, de Mello Brandão AB. Prognostic factors associated with in-hospital mortality in patients with spontaneous bacterial peritonitis. Ann Hepatol. 2012;11:915-920.

28. Townsend L, Blais P, Huh A, Nayak L, Elwing JE, Sayuk GS. Survival benefit associated with early detection of spontaneous bacterial peritonitis in veteran inpatients with cirrhotic ascites. JGH Open. 2019;. https://doi.org/10.1002/jgh3.12290.

29. Schwabl P, Bucsics T, Soucek K, et al. Risk factors for development of spontaneous bacterial peritonitis and subsequent mortality in cirrhotic patients with ascites. Liver Int. 2015;35:2121-2128. https://doi.org/10.1111/liv.12795.

30. Nehra MS, Ma Y, Clark C, Amarasingham R, Rockey DC, Singal AG. Use of administrative claims data for identifying patients with cirrhosis. J Clin Gastroenterol. 2013;47:e50-e54. https:// doi.org/10.1097/MCG.0b013e3182688d2f.

31. Mapakshi S, Kramer JR, Richardson P, El-Serag HB, Kanwal F. Positive predictive value of International Classification of Diseases, 10th revision, codes for cirrhosis and its related complications. Clin Gastroenterol Hepatol. 2018;16:1677-1678. https:// doi.org/10.1016/j.cgh.2018.01.042.

32. Runyon BA. Introduction to the revised American Association for the Study of Liver Diseases Practice Guideline management of adult patients with ascites due to cirrhosis 2012. Hepatology. 2013;57:1651-1653. https://doi.org/10.1002/hep.26359.

33. Patel IJ, Rahim S, Davidson JC, et al. Society of Interventional Radiology Consensus Guidelines for the periprocedural management of thrombotic and bleeding risk in patients undergoing percutaneous image-guided interventions-part II: recommendations: endorsed by the Canadian Association for Interventional Radiology and the Cardiovascular and Interventional Radiological Society of Europe. J Vasc Interv Radiol. 2019;30:1168-1184.e1. https://doi.org/10.1016/j.jvir.2019.04.017.

Publisher's Note Springer Nature remains neutral with regard to jurisdictional claims in published maps and institutional affiliations. 